\title{
Sc-in-zircon by LA-ICP-QQQ-MS provides insights into relative timing and locus of zircon crystallisation in magmatic systems
}

\author{
YANNICK BURET AND SIMON J. E. LARGE
}

Natural History Museum

Presenting Author: y.buret@nhm.ac.uk

Zircon geochemistry is a powerful indicator of magmatic processes. However, many trace elements in zircon (e.g. REEs, $\mathrm{Hf}, \mathrm{Th}, \mathrm{U}$ ) are strongly controlled by minor accessory phases (e.g. titanite, monazite), that obscure signatures of major phases (e.g. amphibole, plagioclase). Scandium has modest partition coefficients in accessory phases, however, strongly partitions into amphibole, allowing the discrimination of titanite and amphibole crystallisation. Accurate analysis of Sc-in-zircon is hampered by the ${ }^{90} \mathrm{Zr}^{++}$interference on the ${ }^{45} \mathrm{Sc}^{+}$that requires high mass resolution to resolve $(\mathrm{M} / \Delta \mathrm{M} \sim 12,000)$, thus limiting the measurement of Sc-in-zircon to high resolution ion-probes [1]. We provide a robust method to measure Sc-in-zircon using an Agilent 8900 ICP-QQQ-MS using $\mathrm{O}_{2}$ as a reaction gas to measure ${ }^{45} \mathrm{Sc}^{16} \mathrm{O}^{+}[2]$ together with a suite of trace elements. We demonstrate efficient ${ }^{90} \mathrm{Zr}^{++}$removal in a nominally Sc-free synthetic zircon $(<0.1 \mathrm{ppm} \mathrm{Sc})$. Analysis of common zircon reference materials (91500, GJ-1, MudTank, Temora II) show narrow variations within each reference material, but large variations in Sc concentrations between reference materials $(<1$ $100 \mathrm{ppm})$.

To investigate the geological significance of Sc-in-zircon concentrations we analyse zircons from four porphyries at the Bingham Canyon porphyry $\mathrm{Cu}$ deposit that span a continuous crystallisation duration of $800 \mathrm{ka}$ [3]. Scandium-in-zircon concentrations increase systematically from $\sim 10 \mathrm{ppm}$ in the oldest intrusion to $>100 \mathrm{ppm}$ in the youngest and exhibit strong correlations with Ti-in-zircon temperatures and other fractional crystallisation indicators (e.g. Th/U, Yb/Dy). Monte Carlo simulations modelling Rayleigh fractionation reveal that amphibole was not a major crystallising mineral at the time of zircon crystallisation. This study reveals that the zircons analysed could not have crystallised in a lower crustal amphibole dominated crystallising assemblage that is responsible for the bulk magma compositions at Bingham Canyon. Rather, it supports previous work on Bingham Canyon that zircon crystallisation occurred in a large upper crustal magma reservoir. This work is relevant for crustal magmatic processes and demonstrates that Sc-in-zircon provides additional information about the magmatic conditions where zircons crystallised.

[1] Coble et al., (2018) Geochem. Geophys. Geosyst., 42, 481497.

[2] Sugiyama, N. (2019) Agilent Application Note, 5994$1155 \mathrm{EN}$.

[3] Large et al., (2021), Earth Planet Sc. Lett., In Review. 